Recebido: 31/10/2018

Aprovado: 20/12/2019

\title{
Eugenia, saúde e trabalho durante a Era Vargas
}

\author{
Daniela Teles da Silva ${ }^{1}$
}

Resumo: $O$ início do século $X X$ trouxe consigo a necessidade de modificações em toda a estrutura social, envolvendo o setor econômico, sanitário, educacional e trabalhista. O movimento conhecido como Revolução de 1930 trouxe ao poder Getúlio Vargas, figura que marcou a transição de um modelo agrário-escravista para o urbano-industrial no país. Os caminhos percorridos por Getúlio, principalmente durante 1930 e 1945 - período que comporta a Era Vargas -, apresentaram mudanças nas políticas públicas e sociais. Focando principalmente na questão do trabalho e da saúde, por diversas vezes vinculada aos ideais sanitaristas, eugenistas e higienistas, analisando algumas das intenções da Liga Pró-Saneamento, da Eugenia, e da Liga de Higiene Mental, o objetivo principal deste trabalho é o de compreender qual o propósito de Getúlio Vargas ao apoiar tais medidas em suas políticas, em prol do desenvolvimento da sociedade brasileira.

Palavras-chaves: Era Vargas; Trabalho; Saúde.

\footnotetext{
${ }^{1}$ Graduação em Licenciatura em História pela Universidade Estadual do Centro-Oeste (UNICENTRO PR). Especialização em Metodologia do Ensino de História do Brasil. / daniielateless@gmail.com
} 
Abstract: The beginning of the 20th century brought with it the need for changes throughout the social structure, involving the economic, sanitary, educational and labor sectors. The movement known as the Revolution of 1930 brought to the power Getúlio Vargas, a figure that marked the transition from an agrarian-slave model to urban-industrial in the country. The paths traveled by Getúlio, especially during 1930 and 1945 - a period that includes Vargas' age - presented changes in public and social policies. Focusing mainly on the question of work and health, on several occasions linked to sanitarian, eugenic and hygienist ideals, analyzing some of the intentions of the Pro-Sanitation League, Eugenics, and Mental Hygiene League, the main objective of this paper is to understand the purpose of Getúlio Vargas by supporting such measures in his policies, in favor of the development of brazilian society.

Keywords: Vargas's Age; Work; Health.

\section{Introdução}

A década de 1920 trouxe inúmeros descontentamentos ao Brasil, principalmente em relação à forma de governo no país. A política brasileira se mantinha através das oligarquias estaduais e do coronelismo. O período conhecido por "República Velha" detinha o predomínio dos grupos agrários; governada pela conhecida "política Café com Leite”, ou seja, alianças oligárquicas realizadas com algumas trocas de favores, principalmente entre São Paulo e Minas Gerais (cf. ROSSI, 2001: 2) (cf. MENDONÇA, 1990: 316-321).

Os chamados "coronéis" exerciam o poder entre as famílias, amigos e seus subordinados, controlando votos e ocupando os cargos políticos existentes, tanto em nível estadual, como nacional. Desta forma, concentrando o poder entre poucos, não havia controle e nem mesmo progresso do país (cf. MENDONÇA, 1990: 317-318).

A mobilização social buscava mudanças políticas, visando a ascensão junto ao contexto internacional. Neste mesmo período eclode a crise de 1929, agravando o descontentamento no país que buscava seu progresso e mudanças econômicas.

Antes mesmo da Proclamação da República, o Brasil já apresentava lutas e reivindicações sociais, principalmente por nesse período não existir projetos políticos e sociais que tratassem das necessidades da população. No século XIX as reivindicações centravam-se no ideal de um governo que se preocupasse com os interesses nacionais, com reformas econômicas e sociais. No início do século XX, os movimentos sociais

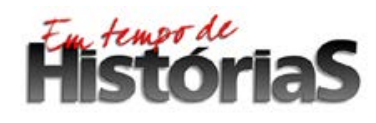

(PPGHIS/UnB) No. 33, Brasília, Ago - Dez 2018 ISSN 2316-1191 
intensificam-se, bem como as medidas políticas para solucionar esses problemas começam moldar-se (cf. RIZOTTI, 2001: 40-42).

Naquele momento de crise emergiu uma figura que não apenas iria encadear as medidas necessárias à industrialização, mas que lançaria as bases para a burocratização nacional. Apoiado pelo Movimento Tenentista, pela ascendente burguesia industrial e parte das classes populares, Getulio Dornelles Vargas promoveu a Revolução de vinte e quatro de outubro de 1930, depondo Washington Luís, decretando Estado de Sítio e instaurando governo provisório (ROSSI, 2001: 7).

O movimento tenentista, juntamente com a Aliança Liberal (partido composto por mineiros, paraibanos e gaúchos, que promoveu a candidatura de Vargas), visava mudanças sociais, bem como, uma nova Constituição; reformulação do sistema jurídicopolítico (que permanecia o mesmo desde 1889); o voto secreto; a reforma agrária e também a independência militar, desvinculando-os dos interesses políticos e oligárquicos (cf. TEIXEIRA, 2000: 245-246), (cf. PANDOLFI, 2010: 16).

Mesmo limitado no seu raio de ação político-ideológica, o movimento tenentista dos anos 20 cumpriu um papel fundamental: expôs as deformações do regime oligárquico, expressou a indignação moral e política do país e ajudou a desestabilizar a República Velha (TEIXEIRA, 2000: 246).

A partir da Revolução de 1930, Getúlio Vargas surge como o governante que acaba inserindo o Brasil no contexto mundial de industrialização, visando à criação de um mercado consumidor interno, marcando o processo de modernismo do Brasil (cf. ROSSI, 2001: 1). Com quatro mandatos presidenciais, Vargas consagrou-se na política. Desde a revolução de 1930 até 1945 passou por três mandatos, e retornou em 1951 quando encerra sua carreira política em 1954 com a tragédia do suicídio.

Passou por regimes constitucionais e autoritários, porém permanecendo com seu caráter nacionalista, populista e carismático, Vargas concebeu uma era. Ficou conhecido como o "pai dos pobres”, o criador das leis trabalhistas e sindicalistas - o maior marco de sua jornada política, sendo exemplo até hoje (cf. CABRAL, 2016: 35-36).

Diversos autores abordaram temas distintos sobre o Governo Vargas. D’Araujo (2010) analisa as questões sociais do governo, comportando o período de 1930 a 1945. Enfatizando o movimento operário e sindical, busca examinar as mudanças a respeito da organização do trabalho e seus impactos na sociedade da época.

\section{Filstortorias}


Mendonça (1990) e Teixeira (2000) apresentam a cronologia do governo de Vargas, relatando a Revolução de 1930 até a chegada do Estado Novo (1937-1945), enfatizando a questão do nacionalismo, apresentando o modelo Corporativista, inspirado no Fascismo, que impulsionou o regime autoritário de Vargas, e como ocorreu sua queda juntamente - e por consequência - da Segunda Guerra Mundial.

Geraldo (2007) expôs as políticas imigratórias do governo, no período de 1930 a 1945, objetivando o controle de estrangeiros, visando o melhoramento racial do Brasil, principalmente durante a Segunda Guerra Mundial (1939-1945), simultâneo ao governo ditatorial de Vargas (1937-1945).

Hochman (2005) descreve e analisa as mudanças políticas voltadas à saúde durante o governo de Vargas, principalmente entre 1934-1945, na gestão de Gustavo Capanema no Ministério da Educação e Saúde. O autor busca elencar as permanências e mudanças nas reformas de saúde, comparando a República Velha com a Revolução de 1930.

Desta forma, este trabalho tem por objetivo apresentar alguns dos caminhos percorridos por Getúlio Vargas durante a Era Vargas, entre 1930 e 1945, perpassando por diversos regimes políticos, modificando as políticas públicas e sociais em prol da ascensão e reconhecimento da nação. Focando principalmente na questão da saúde e do trabalho, que em muito vinculou-se aos ideais da Eugenia, da Liga Pró-Saneamento e da Liga de Higiene Mental, torna-se importante compreender o propósito de Getúlio Vargas ao apoiar e utilizar tais medidas em suas políticas sanitárias e trabalhistas - como a "Lei dos 2/3”, vinculada a lei de imigração e o incentivo de uma educação que influenciasse na higienização da população - em busca do desenvolvimento social do Brasil.

\section{Getúlio Vargas: cronologia política}

Getúlio Dornelles Vargas foi o presidente com mais tempo de governo do país. Em seus 40 anos de vida pública exerceu alguns cargos, tendo maior importância e reconhecimento após 1930 quando “foi chefe do Governo Provisório (1930-1934), presidente da República eleito pela Constituinte (1934-1937), ditador do Estado Novo (1937-1945) e, finalmente, presidente da República eleito com o apoio das massas (19511954)” (CAMARGO, 1999: 16).

\section{Filistororias}


A Revolução de 30, como ficou conhecido o movimento, depõe o governo de Washington Luís e põe fim à chamada República Velha. Devido ao seu carisma, Vargas passava uma ideia positiva para a população que, juntamente com as propagandas do governo, auxiliava no aumento de sua popularidade (cf. D’ARAUJO, 2010: 215), (cf. REIS, 2010: 131).

Em seu discurso de posse, Vargas apresentou o programa do governo provisório, estabelecendo "anistia, saneamento moral e físico, ampliação do ensino público, reforma eleitoral, reforma judiciária, nova política agrícola, reforma tributária, instituição do Ministério do Trabalho e um novo plano ferroviário e rodoviário” (TEIXEIRA, 2000: 268).

O Governo Provisório permanece até 1934. Neste período Vargas passa a governar por meio de decretos, tendo em vista que a Constituição de 1891 fora revogada. Uma série de modificações foram realizadas no setor econômico, trabalhista e eleitoral. Essas modificações acabaram por não agradar parte da população, como a alta patente do exército que não apoiou a Revolução de 1930; os patrões que mostraram forte resistência às novas mudanças estabelecidas; bem como os coronéis que perderam suas influências políticas, desta forma, manifestando-se juntamente em busca de uma nova eleição, em 1932 ocorre o movimento conhecido como Revolução Constitucionalista (cf. PANDOLFI, 2010: 17), (cf. CABRAL, 2016: 27), (cf. BUENO, 2006: 189).

Neste momento Getúlio começa repensar sua forma de governo e, em 1933, através de uma Assembléia Constituinte aprova-se a nova Constituição brasileira, promulgada em 1934. Desta forma, busca pacificar os interesses em conflito “consagrando um Estado tipicamente liberal em alguns aspectos e essencialmente autoritário em outros” (SILVA, 2010: 266).

Vargas inicia seu Governo Constitucional. "De chefe do Governo Provisório, converte-se em presidente eleito por votação indireta, segundo os princípios estabelecidos pela Constituição de 1934” (CAMARGO, 1999: 27). Vargas foi (re)eleito presidente do país por sufrágio indireto (cf. CAPELATO, 2010: 115).

De acordo com a Constituição, Vargas assumiria o governo até 1938, quando uma nova eleição seria realizada, desta vez pelo voto popular, respeitando o regime democrático. Porém, em 1935 dificuldades já começam surgir, Vargas então percebe que o auxílio das forças armadas era fundamental para manter o controle e o poder perante 0 Estado e opositores (cf. MOURELLE, 2015: 454), (cf. MOURELLE, 2015: 26).

\section{Filistororias}


Críticas a respeito do governo surgem, pois segundo a oposição "a Revolução havia se desvirtuado ao apoiar ações autoritárias e próprias do coronelismo, semelhantes às que os próprios revolucionários haviam criticado antes de chegar no poder" (MOURELLE, 2015: 42).

Em resposta, Vargas criou em 1934 o Conselho de Segurança Nacional, buscando governar com mais segurança, promulgando em 1935 a Lei de Segurança Nacional. Desta forma, Vargas visava obter mais poder, censurando, atacando a oposição e impedindo manifestações contrarias (cf. MOURELLE, 2015: 92-96).

O governo de Vargas focou na centralização do poder, mascarando-se por meio de um discurso democrático. Desta forma, em novembro de 1937 - quando intensificavam-se as campanhas eleitorais - com o auxílio dos militares, Getúlio promove o golpe que implanta o Estado Novo, uma espécie de “ditadura pessoal”, ideologicamente semelhante ao regime fascista instaurado na Itália (cf. REIS, 2010: 131), (cf. D’ARAUJO, 2000: 10-15).

Dificilmente se poderá saber em que momento, entre 1934 e 1937, Getúlio Vargas se decidiu pelo golpe. Primeiro, porque Getúlio manteve-se tanto quanto possível na penumbra, deixando à frente das manobras seus ministros militares ou seus amigos de última hora, os integralistas. Mas, sobretudo, porque Vargas usou de todo seu feeling político para conduzir o golpe de Estado como uma cirurgia de baixo risco, suave, aceita como inevitável. E conseguiu. Nas primeiras horas da manhã de 10 de novembro de 1937, o Diário Oficial comunicava a implantação do Estado Novo (TEIXEIRA, 2000: 275).

Mantendo o poder um tanto quanto centralizado e articulando-se, Vargas estabeleceu poder absoluto perante o Estado, fortificando-o a fim de acabar com movimentos opositores. Apresentou-se como um líder carismático “encarregado de gerar as mudanças consideradas necessárias para promover o progresso dentro da ordem” (CAPELATO, 2010: 110), (cf. GERALDO, 2007: 6).

Inspirando-se no Corporativismo, importantes mudanças foram implantadas no Brasil. Novas formas de controle social, uma nova forma de pensar a política, a inserção de novas leis trabalhistas, a criação do Departamento de Imprensa e Propaganda (DIP) estabelecendo controle e censura, são alguns aspectos do novo governo Vargas (cf. CARDOSO, 2007: 112). Estabelecendo "autoritarismo político e ideologia nacionalista extremada” (D’ARAUJO, 2000: 12).

\section{Filstotorias}


Desde o início da Era Vargas são criadas políticas públicas com o objetivo de promover Vargas, inserindo-o no cotidiano dos trabalhadores e ganhando maior visibilidade, porém em 1939 cria-se o Departamento de Imprensa e Propaganda (DIP), visando não apenas a censura dos meios de comunicação, mas também intensificar a propaganda do governo de Getúlio Vargas (cf. REIS, 2010: 132).

Criando símbolos, mitos, representações e cerimônias cívicas para legitimar o novo governo, utilizando-se dos veículos de comunicação da época, a reorganização do Estado e da economia foram pontos de extrema importância nesse período, com o autoritarismo estabelecido houve grande controle político, cultural e social (cf. CAPELATO, 2010: 111-113).

O Estado Novo manteve-se até 1945. A Segunda Guerra Mundial teve papel fundamental na queda do regime ditatorial de Vargas, pois sua forma de governo já não cabia aos moldes do novo sistema econômico e social que se legitimava (cf. CAPELATO, 2010: 113). No início da guerra em 1939, o Brasil manteve neutralidade, pois o governo possuía relações comerciais tanto com os Estados Unidos, como com a Alemanha, porém com a pressão norte-americana, em 1942 o Brasil rompe as relações comerciais e diplomáticas com os países do Eixo (Alemanha, Itália e Japão) em troca do auxílio dos Estados Unidos (cf. GERLADO, 2007: 147; 196).

Manifestações começam ocorrer por todo o país reunindo trabalhadores, estudantes, empresários e políticos contrários ao nazismo e favoráveis à democracia e à liberdade de pensamento (cf. TEIXEIRA, 2000: 280-282). “As contradições do Estado Novo, um regime internamente autoritário e externamente favorável à democracia, tornaram-se explícitas e isto enfraqueceu o prestígio do 'ditador', que passou a ser alvo de oposição sistemática” (CAPELATO, 2010: 136).

Neste momento, percebendo que o fim do seu governo aproximava-se, Vargas iniciou o processo de democratização política. Os movimentos contrários e os opositores começaram surgir com maior intensidade e novos candidatos foram apresentados. Desta forma, em fevereiro de 1945 através de um Ato Adicional, as eleições são marcadas para maio deste mesmo ano, concretizando o fim do Estado Novo (cf. TEIXEIRA, 2000: 281283), (cf. CAPELATO, 2010; 136-138).

Em 1945, quando se inicia o processo de democratização do país, surge uma convulsão popular conhecida como “Queremismo”. A população clamava para que Vargas continuasse na presidência.

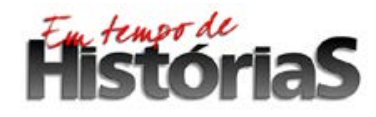

(PPGHIS/UnB) No. 33, Brasília, Ago - Dez 2018 ISSN 2316-1191 
Naquele momento, enquanto os alicerces da ditadura estadonovista encontravam-se frágeis diante dos novos tempos, uma ampla multidão mobilizou-se nas ruas do país, reivindicando a permanência de Vargas no poder. Entre os getulistas, encontravam-se políticos que participaram do Estado Novo, empresários que se enriqueceram naquele regime, funcionários públicos que se beneficiaram dele, mas, sobretudo, setores populares (MACEDO, 2008:10).

Os trabalhadores temiam perder os direitos e benefícios conquistados com o governo de Getúlio. Como sua permanência não cabia aos novos moldes políticos e sociais da época, dois partidos surgem: o Partido Social Democrático (PSD) e o Partido Trabalhista Brasileiro (PTB). O PSD integrava os governantes do Estado Novo e grandes proprietários rurais, era um partido voltado à elite; enquanto o PTB integrava os principais líderes sindicais, além de trabalhadores buscando permanecer com a herança de Vargas (cf. MACEDO, 2008: 18-19).

Desta forma percebe-se que “derrotado foi o Estado Novo, e não seu presidente, que voltaria ao poder em 1951, escolhido pelo voto e com a preferência de amplos setores sociais, populares principalmente” (CAPELATO, 2010: 139).

Vargas ficou conhecido como o defensor dos direitos trabalhistas, apesar de grande parte de seu governo manter características de Estado forte, politicamente e economicamente centralizado, com a censura e o controle das massas.

\section{Instituições, ministérios e trabalho}

A lembrança de Getúlio Vargas geralmente é associada ao trabalhismo e sindicalismo, isso porque o período de 1930 a 1945 teve em suas bases o amplo desenvolvimento das políticas públicas, em especial, vinculadas ao trabalho, neste período houve criação e regulação de leis trabalhistas que perpassaram a Era Vargas (cf. D’ARAUJO, 2010: 215).

O período anterior à Proclamação da República já apresentava reivindicações e lutas sociais, e na Primeira República já havia uma estrutura de legislação trabalhista, porém não era vinculada a questões políticas, mas sim como um problema moral e sanitário. Por não existir uma política social concreta que auxiliasse a população, as greves foram agravadas com o passar dos anos, ganhando maior visibilidade na sociedade. Em 1917, por exemplo, os trabalhadores de São Paulo reuniram-se reivindicando a redução da jornada de trabalho e a regulamentação do trabalho,

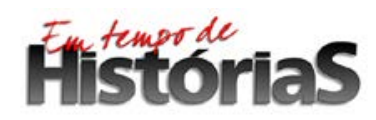


principalmente o feminino e infantil, ocasionando em uma greve geral (cf. RIZOTTI, 2001: 42), (cf. FEE, 1983, p. 22).

Alguns anos mais tarde, em 1925, eclodiu a Coluna Prestes que, por dois anos percorreu o país organizando movimentos populares contra as más condições sociais, visando os direitos políticos e civis da população, bem como o direito ao voto secreto e voto feminino.

Neste período não havia uma política social eficiente para auxiliar nas questões de educação, saúde e saneamento. As agitações trabalhistas eram contidas pela força policial, não havia ministérios ou leis que atendessem essa classe, até 1923, quando começam tratar das questões previdenciárias, porém somente a partir de 1930, surge um novo modelo político e social (cf. RIZOTTI, 2001: 43), (cf. FEE, 1983: 17-18).

Ao assumir o poder, [Vargas] tomou medidas que já anunciavam uma nova maneira de encarar o desenvolvimento do país dentro da ordem. Criou o Ministério do Trabalho, que se responsabilizou pela formulação de novas leis referentes ao mundo do trabalho e pela fiscalização da observância das que já existiam; tais medidas significavam o atendimento de uma reivindicação antiga dos trabalhadores brasileiros, mas também o controle do Estado nas relações entre patrões e operários (CAPELATO, 2010: 115).

A organização do trabalho teve enorme importância, principalmente devido ao momento de transição em que o país passava, desvinculando-se da dependência total de um sistema agrário e substituindo-o por um sistema econômico urbano-industrial. O primeiro Ministro do Trabalho, Lindolfo Collor, vinculou as legislações já existentes para o debate político, auxiliando na implementação e regulamentação de outras leis. Considerado a principal figura a impulsionar as leis sociais e trabalhistas do país, muito do que surgiu em termos de legislação, teve sua influência (cf. BARBOSA, 2013: 24).

Getúlio buscou assumir a responsabilidade e o controle da ascensão dos trabalhadores desde o início do Governo Provisório, criando o Ministério do Trabalho, Indústria e Comércio e o Ministério da Educação e Saúde Pública. Além de diversas leis e decretos que visavam à proteção do trabalhador, atendendo antigas reivindicações, como a definição da jornada de trabalho em oito horas, o repouso semanal, férias remuneradas, a instauração do salário mínimo, a aposentadoria por idade, regulamentação do trabalho infantil e feminino, entre outras questões trabalhistas; o que auxiliou em muito na promoção do governo, principalmente perante as mais baixas camadas sociais (cf. GOMES, 1999: 53-55), (cf. FEE, 1983: 23-25), (cf. PANDOLFI, 2010: 19).

\section{Filistororias}


Visando controlar a economia do país, em 1931 Vargas criou o Conselho Nacional do Café, que em 1933 tornou-se o Departamento Nacional do Café. Em 1932 foi criado o Instituto do Cacau, e em 1933, o Instituto do Açúcar e do Álcool (cf. PANDOLFI, 2010: 20-21). Em 1932 Vargas editou o Código Eleitoral, estabelecendo o voto secreto e inserindo o voto feminino, dando bases para a criação da Justiça Eleitoral neste mesmo ano (cf. ROSSI, 2001: 4), (cf. PANDOLFI, 2010: 23).

A criação de um modelo único de Sindicato em 1931, através do Decreto-lei n. 19.770, auxiliou no controle das leis trabalhistas e na criação da Justiça do Trabalho em 1939, na regulamentação do salário mínimo em 1940, e na criação da Consolidação das Leis do Trabalho em 1943 (cf. PANDOLFI, 2010: 19-20), (cf. TEIXEIRA, 2000: 279).

O Estado passou a intervir diretamente nas questões sociais, em especial, em políticas trabalhistas, o regime teve por modelo político, econômico e social, o Corporativismo. Este modelo influenciou na criação do Ministério do Trabalho, Indústria e Comércio e nas leis sindicalistas (cf. REIS, 2010: 134).

Atendendo antigos anseios dos trabalhadores, Vargas se legitima. Na medida em que a industrialização ia crescendo no país, a legislação trabalhista moldava-se para encaixar-se no contexto de modernização vigente. A manutenção da força de trabalho garantia sua capacidade produtiva, ou seja, dando melhores condições de trabalho e estabelecendo leis para os trabalhadores, assegurava-se a sua existência e seu desenvolvimento, o que auxiliava no progresso da nação (cf. FEE, 1983: 34-35), (cf. RIZOTTI, 2001: 44).

Os sindicatos exerciam funções públicas, influenciados e subordinados pelo governo através do Ministério do Trabalho, visando o controle dos trabalhadores e suas respectivas atividades, evitando as greves, conflitos e a luta de classes, ou seja, movimentos operários que oferecessem risco à "harmonia” estabelecida. Assim o Estado trabalhava; cedendo um espaço de organização aos trabalhadores e, por outro lado, acabava por restringir as ações realizadas pelos mesmos (cf. D’ARAUJO, 2010: 217223). Ou seja, "Vargas reconheceu os trabalhadores através dos sindicatos, mas não as liberdades políticas. E sem liberdade política, os direitos trabalhistas - bem como qualquer direito - nunca estarão completos” (D’ARAUJO, 2010: 237).

Servindo aos interesses públicos e não aos particulares dos trabalhadores, os sindicatos nasciam e seguiam “à sombra do Estado, sua origem e extinção eram decisões estatais” (D’ARAUJO, 2010: 225). A dependência total dos sindicatos ao Estado 
evidencia-se em 1939, e todos deveriam ser registrados no Ministério do Trabalho para garantirem seu reconhecimento, e também como forma do controle governo. A Consolidação das Leis de Trabalho (CLT) aprovada em 1943 reafirma essa necessidade de fiscalização (cf. MOURELLE, 2015: 70). Vale lembrar que

a lei sindical da era Vargas, enquanto concedia benefícios e direitos aos sindicalizados, também estipulava que os sindicatos só poderiam servir aos trabalhadores desde que seus interesses fossem coincidentes com os do governo em vigor (D’ARAUJO, 2010: 231).

Para auxiliar na fiscalização dos trabalhadores, já em 1932 foi criada a Carteira de Trabalho que, por décadas foi considerada o documento de maior importância entre os brasileiros, pois através dela era registrada toda a vida profissional dos trabalhadores, além de auxiliar na aposentadoria. Quando criada, a carteira de trabalho tinha uma importante impressão:

A carteira, pelos lançamentos que recebe, configura a história de uma vida. Quem examina logo verá se o portador é um temperamento aquietado ou versátil; se ama a profissão escolhida ou se ainda não encontrou a própria vocação; se andou de fábrica em fábrica como uma abelha, ou permaneceu no mesmo estabelecimento, subindo a escala profissional. Pode ser um padrão de honra. Pode ser uma advertência (D’ARAUJO, 2010: 233).

Assinada por Alexandre Marcondes Filho - Ministro do Trabalho na época -, essa apresentação demonstrava a importância e o peso que o trabalhador carregava. O trabalho era o que dignificava o homem, era a principal função para estimular e desenvolver a economia e o país, possibilitando um melhor padrão de vida às famílias brasileiras (cf. GOMES, 1999: 71).

A criação da carteira de trabalho auxiliou na proibição do trabalho noturno e do trabalho aos menores de 14 anos, estabeleceu uma carga horária para os trabalhadores, regularizou o trabalho feminino e iniciou o processo de proteção às gestantes. Mesmo com a insatisfação de alguns patrões e empresários, com o tempo, todos tiveram a obrigação de cumprir com o que foi imposto (cf. D’ARAUJO, 2010: 234).

Valorizando o papel e o lugar do trabalhador brasileiro, criando políticas previdenciárias e sindicais, resulta-se na criação da Justiça do Trabalho. Criada com a Constituição de 1934, só foi devidamente “inaugurada” em 1941, numa época marcada pelo autoritarismo, o objetivo da Justiça do Trabalho era reforçar o controle total dos

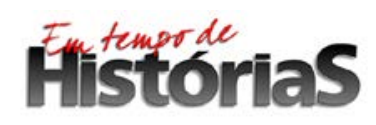


trabalhadores, impedindo as greves e movimentos contrários ao Estado (cf. GOMES, 1999: 53-55), (cf. D’ARAUJO, 2010: 232).

Porém, o grande número de modificações sociais e trabalhistas não agradou grande parte dos trabalhadores e seus patrões, que iniciam inúmeras greves e manifestações, que intensificam-se entre 1934 e 1935, e sem fazer valer o uso das leis impostas, Vargas utilizou a força policial como meio de repressão e "solução" dessas questões sociais, da mesma forma como era feito anterior a Revolução de 1930 (cf. BATISTELLA, 2015: 27).

Com os problemas evidenciados, a repressão aos trabalhadores volta a ser estabelecida, principalmente com o novo Ministro do Trabalho, Agamenon Magalhães, que entre 1934 e 1937 incentivou a coibição aos sindicatos.

Assim, a escolha de Agamenon para o Ministério do Trabalho teve um amplo sentido: não mais haveria competição entre propostas concorrentes, nem lutas nos sindicatos ou nas ruas, pois a repressão [...] tornaria inviável qualquer tipo de ação independente surgida do interior da classe trabalhadora (BATISTELLA, 20015: 28).

Moldava-se o novo modelo de governo, que implantado em 1937 com uma nova Constituição, demonstrou os reais interesses de Vargas, com um Estado forte e centralizado, controlando as massas em função do processo de industrialização e desenvolvimento nacional, bem como legitimar e promover seu governo (cf. FEE, 1983, p. 31-35).

As Constituições de 1934 e 1937 enfatizavam a importância do trabalho, impondo ligações entre o governo e os trabalhadores, criando direitos trabalhistas ao mesmo tempo em que repreendiam o trabalhador, configurando em crime viver no ócio. Principalmente durante o Estado Novo (1937-1945), houve aumento nas estratégias políticas centradas no trabalhismo, objetivando evidenciar o valor do trabalho perante a sociedade (cf. BRASIL, 1934), (cf. BRASIL, 1937).

A criação do salário mínimo foi realizada em 1940 através do Decreto n. 2.162 garantindo uma remuneração mínima aos trabalhadores, e com o Decreto n. 2.474 de 1940, estabeleceu-se ao trabalhador o limite de 60 anos para aposentar-se. Portanto, para que os trabalhadores pudessem gozar desses direitos, deveriam estar associados aos sindicatos reconhecidos pelo Estado, lembrando que essas leis e direitos eram estabelecidas aos trabalhadores urbanos, excluindo grande parte da população brasileira que trabalhava na agricultura (cf. D’ARAUJO, 2010; 235), (cf. REIS, 2010: 126).

\section{Filistortion}


Desta forma, o governo buscava incentivar os trabalhadores urbanos, uma vez que o processo de industrialização estava em evidência. Desenvolveu-se a crença que a partir do trabalho e das leis trabalhistas, a promoção da economia e o desenvolvimento do país se daria de forma mais rápida e eficaz. Valorizando o trabalho, o homem acabava por valorizar a si mesmo, bem como sua nação (cf. GOMES, 1999: 55).

Concomitante a isso, em 1941 foi criada a Companhia Siderúrgica Nacional (CSN), incentivando a indústria pesada e, por consequência, o desenvolvimento da economia nacional. Assim as leis trabalhistas que visavam à segurança do trabalhador, bem como férias e benefícios adicionais, foram intensificados, pois com a industrialização em desenvolvimento, certas garantias deveriam ser atribuídas aos trabalhadores, para garantir o progresso do país de forma rápida e segura, mesmo que essas leis fossem, em sua maioria, estabelecidas somente no papel.

Quando Vargas deixa o poder em 1945, ele já era considerado o maior líder populista do país, principalmente por conta das leis sociais e pela legislação trabalhista que foram implantadas durante seu governo (cf. D’ARAUJO, 2010: 236).

Porém a implementação dos ministérios e a legislação trabalhista, bem como a criação da CLT, não eram garantia total nas relações e direitos trabalhistas; nem tudo que estava escrito era concedido aos trabalhadores e, inúmeras vezes, os sindicatos frustraram-se tanto com os empregadores como com o governo, que não cumpriam com a lei. Apesar de a CLT só existir no papel e, no início pouco ser utilizada em prol dos trabalhadores, ela formou a base da consciência e da luta de classes dos trabalhadores, modificando a visão e o comportamento dos mesmos, que acabam percebendo os seus direitos (cf. BOLZAM, 2001: 208-209).

Construindo laços com diversos grupos sociais, em especial, os trabalhadores, atendendo suas reivindicações mesmo que de maneira limitada, houve um intenso "jogo político” onde Vargas oferecia direitos em troca de apoio. As políticas trabalhistas foram essenciais para legitimar o governo, que consagrou importantes conquistas como a Carteira de Trabalho, a CLT e o salário mínimo, que são alguns dos aspectos mais significativos do governo Vargas, e com algumas modificações, permanecem entre nossos direitos trabalhistas até hoje.

\section{Eugenia, saúde e higiene}


Com Getúlio Vargas no governo, o Brasil iniciou um processo de mudanças sociais, trabalhistas e sanitárias:

De um lado, a industrialização, a imigração e a urbanização das principais cidades pintavam um novo cenário para o Brasil; por outro, os efeitos devastadores da Primeira Guerra Mundial causavam grande impacto nas elites política e intelectual brasileiras, forçando-as a voltar seus olhos para dentro do seu próprio país (SOUZA, 2012: 4).

Tendo em vista que o Brasil inicia sua transição para um modelo urbanoindustrial, busca-se uma identidade própria para a nação configurando-se a um novo modelo político e econômico. Com o processo de formação da nova sociedade brasileira, questões a respeito da identidade nacional começam a ganhar relevância, bem como a saúde e a higiene começam ser repensadas e programas sociais surgem conforme o processo de industrialização intensifica-se (cf. ROCHA, 2014: 3), (cf. SOUZA, 2012: 4$5)$.

Para os sanitaristas, a falta de hábitos higiênicos era um dos grandes fatores relacionados à proliferação de doenças, desta forma, era preciso higienizar, limpar e tratar a população visando um bem maior (cf. PONTE, 2010: 55).

Na visão de Belisário Penna, Arthur Neiva, Miguel Pereira e demais lideranças da Liga Pró-Saneamento do Brasil [criada em 1918], a precariedade das condições de salubridade e o abandono a que estava submetida boa parte da população brasileira deviam-se, em última análise, à ausência e inoperância do poder público, que não chamava a si a responsabilidade de zelar pela saúde do povo a quem devia servir (PONTE, 2010: 96).

Influenciado pelos sanitaristas da Liga Pró-Saneamento do Brasil, Vargas estabelece através do Decreto n. 19.402 o Ministério dos Negócios da Educação e Saúde Pública em 1930. A partir de então, políticas de saneamento visando melhorar as condições de trabalho e moradia, começam ser repensadas buscando eliminar as doenças e epidemias que se propagavam com mais facilidade, principalmente entre os trabalhadores que detinham importante papel no desenvolvimento do país (cf. FEE, 1983: 29), (cf. FONSECA, 1993: 105-109), (cf. PONTE, 2010: 100).

Resultado de uma nova mentalidade, a Liga Brasileira de Higiene Mental (LBHM) surgiu em 1923 através do Decreto n. 4.778, sendo consequência da conjuntura política que surge após o término da Primeira Guerra Mundial. Através da LBHM manifestou-se

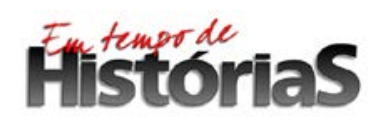


o sentimento nacionalista, onde os higienistas - assim como os sanitaristas -, buscavam eliminar os males da nação (cf. REIS, 1994: 51-56).

Concomitante a isso, a Eugenia, que tem seu auge nos anos 1920, começa ser discutida no governo Vargas, visando estimular a formação da identidade brasileira "já que sua atuação previa uma ampla reforma social, principalmente nos valores estéticos, nos hábitos higiênicos, na conduta pública, na educação intelectual e nos valores morais ligados a sexualidade” (SOUZA, 2012, p. 7).

Desta forma, percebe-se que tanto os sanitaristas, como os higienistas e os eugenistas objetivavam pelo progresso da nação, buscando melhorias na saúde e educação da população brasileira, o que também era o ideal de Vargas (cf. PONTE, 2010: 98).

Durante as primeiras décadas do século, houve grande preocupação com um projeto para a nação, onde o foco estava justamente na construção física e moral da população para definir o que era ser brasileiro. Neste momento, o Estado acaba por intervir, fornecendo melhores condições sanitárias e educacionais, visando educar e sanar a população (cf. PONTE, 2010: 75).

Objetivava-se criar um "homem novo". Os programas de saneamento influenciaram diretamente nas políticas sociais do governo, pois os ideais sanitaristas coincidiam com os ideais de Vargas. Os sanitaristas apontavam o brasileiro como um povo doente e analfabeto, e somente através da saúde e da educação, o país conseguiria livrar-se, do seu atraso social (cf. PONTE, 2010: 76-77), (cf. D’ARAUJO, 2000: 7).

Desta forma, mudanças foram intensificadas em prol do progresso, visando criar uma sociedade predominantemente branca e alfabetizada, inspirada nos moldes sociais europeus. Os cuidados em relação à educação e saúde reforçam-se; inicialmente preocupava-se com as doenças transmissíveis, principalmente as que possuíam risco de epidemia, uma vez que atingindo grande número populacional acabaria afetando a economia. A luta contra essas doenças estão vinculadas ao ideal da formação e construção de um Estado forte e nacionalista, tendo como principal foco os trabalhadores, imigrantes e os jovens (cf. ROCHA, 2014: 2), (cf. SOUZA, 2012: 4), (cf. PONTE, 2010: 113), (cf. D’ARAUJO: 2000: 34).

Neste momento surgem campanhas a favor da seleção dos imigrantes, e debates sobre a implementação de uma educação voltada aos ideais eugênicos, bem como a inserção de exames pré-nupciais que, inclusive, foram objetivos estabelecidos na Constituição de 1934 (cf. SOUZA, 2012: 16).

\section{Filistortion}


A gestão de Gustavo Capanema no Ministério da Educação e Saúde Pública, entre 1934 a 1945, foi fundamental para a consolidação das políticas de saúde pública; modificou o nome para Ministério da Educação e Saúde (MES), e em 1941 houve a criação dos Serviços Nacionais, o que auxiliou nas campanhas contra endemias, epidemias e no combate a diversas doenças (cf. HOCHMAN, 2005: 131).

O modelo político e ideológico de governo estimulava a Eugenia, principalmente no que diz respeito à formação de uma nacionalidade, modificando as políticas sanitárias, em especial, vinculadas à imigração (cf. SOUZA, 2012: 15).

Em 1930, através do Decreto n. 19.482, Vargas já limitava a entrada de imigrantes no país. Além de instituir a “Lei dos 2/3” que obrigava as empresas terem pelo menos 2/3 de funcionários brasileiros, reservando apenas 1/3 das vagas aos imigrantes. A partir dessas medidas, visava defender o trabalhador nacional, controlar a imigração, além de conter a “desordem econômica e a insegurança social” (GERALDO, 2007: 1).

Durante o século XIX foram criadas políticas que estimulavam a vinda de imigrantes ao Brasil, com o objetivo de povoar e desenvolver o país. Com o início do século XX, a imigração passa a ter outro objetivo, influenciados pela Eugenia, buscando criar uma identidade para nação através de características fortes e marcantes, as políticas imigratórias passam a banir a entrada de determinados grupos ao país, com o pressuposto que não possuíam características decisivas para o desenvolvimento da nação (cf. SIKORA, 2014: 49-52).

O governo intensificou os debates buscando estabelecer uma identidade aos brasileiros, principalmente voltada ao ideal racial, desta forma, impedindo a imigração de raças consideradas inferiores (cf. SOUZA, 2012: 17), (cf. GERALDO, 2007: 23). "Os artigos sobre imigração foram mantidos na Constituição promulgada pelo Estado Novo em 1937, ratificando o compromisso com o branqueamento do Estado nacional e reforçando o mito da unidade nacional” (STEPAN, 2004: 379).

Auxiliando na propagação das políticas imigratórias, o Boletim do Ministério do Trabalho, Indústria e Comércio, teve publicações durante as décadas de 1930 e 1940 vinculadas a projetos e ideais de povoamento, ocupação e distribuição de territórios. Em 1938 foi criado o Conselho de Imigração e Colonização, a partir de 1940 começam as publicações da Revista de Imigração e Colonização e na Revista Cultura Política, onde leis e teorias eugenistas eram divulgadas, bem como a classificação dos imigrantes, do

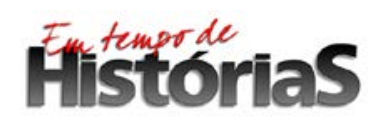


pior ao melhor, demonstrando suas condições mentais e físicas (cf. GERALDO, 2007: $30-42)$.

O Governo Federal reservava-se o direito de limitar ou suspender, por motivos econômicos ou sociais, a entrada de indivíduos de determinadas raças ou origens, ouvido o Conselho de Imigração e Colonização (Art. $2^{\circ}$ ) (BRASIL, 1938). Essa legislação do Estado Novo reflete os pressupostos de eugenia, com restrições para entrada de doentes, aleijados, pessoas de condutas indesejáveis, apontando para os critérios raciais (SIKORA, 2014: 60).

Para auxiliar na classificação dos imigrantes, Vargas utilizou-se da Eugenia que foi criada em 1883 por Francis Galton. Essa ciência estudava o melhoramento biológico da espécie através da hereditariedade; determinadas características definiam a superioridade ou inferioridade dos indivíduos, havendo uma hierarquia de raças, onde a raça branca, européia, era considerada a mais nobre. Desta forma, através de alguns estudos, selecionava-se a população apta a reproduzir-se - incentivada por políticas públicas, médicos e sanitaristas. Essa parte da população é que determinaria o desenvolvimento e progresso do país (cf. GERALDO, 2007: 11), (cf. SCHNEIDER, MEGLHIORATTI, 2012: 5).

Através dessas inquietações os cientistas e sanitaristas “divulgavam o discurso ideológico de estimular a reprodução entre pessoas com características desejáveis eugenia positiva - e desestimular a reprodução entre os doentes e incapacitados - eugenia negativa” (SCHNEIDER, MEGLHIORATTI, 2012: 6). Com um discurso nacionalista, associando-se ao patriotismo almejado pelo governo Vargas, os eugenistas encontravam espaço para legitimar-se (cf. SOUZA, 2012: 16).

Muitos foram os aspectos que caracterizaram a eugenia nos anos 1930. A questão racial e as discussões sobre a identidade nacional juntaramse aos discursos sobre gênero, higiene, sexualidade, educação eugênica, alcoolismo e doenças venéreas, entre outros, formando uma agenda reformista aceita para boa parte da elite brasileira (SOUZA, 2012: 18).

Buscando controlar os "problemas sociais", tratando de delinquentes juvenis, pobres, ou portadores de doenças mentais, Vargas utilizou-se do poder do Estado e da Eugenia para modificar a parcela da sociedade que dificultava o desenvolvimento do país (cf. STEPAN, 2004: 374). Durante seu governo houve constante preocupação com um novo modelo de brasileiro, com a raça e com o desenvolvimento da sociedade, desta 
forma a criança tinha um papel fundamental, pois através dela se garantiria um futuro melhor (cf. KOBAYASHI, et. al., 2009: 344). Como explica Fonseca (1993), houve

\begin{abstract}
preocupação com a formação de um "novo homem" e de uma "nova raça" que, aliada aos princípios da eugenia e ao ideal de valorização do trabalho, irão alimentar a ênfase na criança como futuro cidadão/trabalhador. Esse conjunto de idéias apresentava como suporte o ideal mais amplo do nacionalismo, marcando as propostas do governo no setor de saúde (FONSECA, 1993: 99).
\end{abstract}

Temas como higiene, salubridade e combate às epidemias, foram prioridade, desde o Governo Provisório. Desta forma, a Eugenia se estabeleceu durante o governo de Getúlio, para auxiliar na conscientização da população a respeito de temas como saneamento, higienização e orientação sexual e influenciando nas modificações de seguridade social, nos benefícios aos trabalhadores e no auxilio maternidade, ainda levando em consideração o importante papel da criança para o futuro do país (cf. STEPEN, 2004: 376), (cf. ROCHA, 2014: 4).

Desde o início da Revolução, Getúlio já havia posto em pauta assuntos como proteção a infância, maternidade, família e também às questões trabalhistas. Desta forma, é inegável que a saúde e a educação eram fundamentais para a consolidação de um Estado forte e unificado. Era preciso curar os doentes e educar a população para livrar-se da degeneração e atingir o tão sonhado progresso (cf. KOBAYASHI, et. al., 2009: 342).

Segundo Vargas “o Estado precisava compor-se de cidadãos selecionados por meio de processos eugênicos, saudáveis física e mentalmente, e para tanto impunha-se a tarefa de proteger e assistir a maternidade, a infância e a juventude” (SOUSA, 2000, p.247).

Tanto a Liga Pró-Saneamento (1918), a Sociedade Eugênica de São Paulo (1918), como a Liga Brasileira de Higiene Mental (1920) “exigiam a intervenção do Estado para solucionar a precária situação da saúde pública no Brasil, condição indispensável, conforme a ótica médica, para a construção da nação” (MARQUES, 2007: 12).

Através dos ensinamentos influenciados e submetidos pela LBHM e pela Eugenia, os jovens deveriam adquirir consciência sanitária e eugênica, criando uma nova mentalidade a respeito da regeneração da raça para o bem coletivo. A educação deste período reforçava o ideal moral eugênico dos bons costumes, com o melhoramento no condicionamento físico para que uma nova população racial forte e nobre fosse concebida (cf. SCHNEIDER, MEGLHIORATTI, 2012: 6).

\title{
Filistororias
}


A LBHM foi criada com o objetivo de auxiliar no desenvolvimento da nação, entre seus objetivos estava o combate ao alcoolismo, controle imigratório, controle matrimonial e esterilização dos seres considerados degenerados, visando auxiliar no processo de melhoramento racial, desta forma a LBHM uniu-se com a Eugenia, visando acabar com as “imperfeições” da sociedade em prol do progresso da nação (cf. MARQUES, 2007: 12-14).

Esses institutos tinham um projeto nacionalista, tendo como prioridade garantir o combate aos vícios sociais, além de auxiliar na saúde mental, na seleção e orientações sexuais, tendo como principal preocupação a infância, pois a partir dela é que se estabelecem as bases para o futuro (cf. REIS, 1994: 55-56).

Influenciada pelos movimentos sanitários, eugênicos e higiênicos, a Constituição de 1934, no Art. 138, determinava ser dever da União, dos Estados e Municípios estimular a educação eugênica, além de cuidar e incentivar a higiene mental e social, impedindo a propagação de doenças transmissíveis, bem como a prática de um melhoramento sanitário e, principalmente, racial (cf. BRASIL, 1934), (cf. ROCHA, 2014: 12).

Formando uma elite nacional aperfeiçoada, essas instituições davam aos jovens a consciência de que era preciso unir-se com pessoas da mesma etnia e classe social, a partir das teorias a respeito da hereditariedade, buscando evoluir como ser humano e dar aos seus filhos as boas características que possuíam (cf. ROCHA, 2014: 6-9).

A Constituição de 1937 ressalta a importância de uma educação eugênica, desenvolvida a partir da disciplina de Educação Física, que se tornou obrigatória em todas as escolas, visando um “melhoramento estético" (cf. D’ARAUJO, 2000: 38), (cf. ROCHA, 2014: 9). O Art. 131 da Constituição de 1937 detinha que:

A educação física, o ensino cívico e o de trabalhos manuais serão obrigatórios em todas as escolas primárias, normais e secundárias, não podendo nenhuma escola de qualquer desses graus ser autorizada ou reconhecida sem que satisfaça aquela exigência (BRASIL, 1937).

Porém, além das crianças havia outra parcela de fundamental importância - os trabalhadores. Associada ao setor previdenciário, a saúde dos trabalhadores detinha grande importância para a economia e o desenvolvimento do país (cf. PONTE, 2010: 117). O cidadão, como bom trabalhador desenvolveria o Brasil, pois o progresso é produto do trabalho, desta forma, o trabalhador tem um papel essencial para o país (cf. GOMES, 1999: 57).

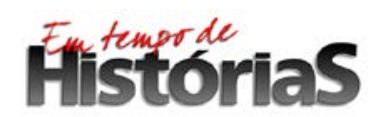


Para Getúlio Vargas, o trabalho não era apenas um meio de "ganhar a vida”, mas principalmente, um meio de “servir a pátria”. De 1930 a 1937 houve uma vasta mobilização a respeito da saúde e das condições de trabalho; neste período surgem os seguros contra acidentes, doença, morte, invalidez, e também o seguro-maternidade, todos visando à segurança e proteção do trabalhador (cf. GOMES, 1999: 59-60).

As políticas educacionais e sanitárias desenvolvidas após 1930 objetivavam a formação do cidadão brasileiro, apto ao trabalho, instruído e higienizado. Acreditava-se que somente melhorando a raça e evidenciando as melhores características da população, estimulando a saúde pública, o Brasil conseguiria atingir seus objetivos (cf. ROCHA, 2014: 9).

Os discursos, campanhas e políticas inspiradas nos ideais eugênicos contestavam a realidade social da época. Os negros, indígenas e portugueses - que formavam a miscigenação racial brasileira - foram inferiorizados, pois contrariavam o ideal de pureza racial do modelo eugênico europeu, desta forma, as políticas sanitárias e imigratórias estabelecidas pelo governo Vargas, foram excludentes (cf. SOUZA, 2012: 4-5).

Com ideais contrários, alguns intelectuais buscavam mostrar a importância da miscigenação na formação da identidade brasileira, identificando esses grupos como fortes e saudáveis, sendo fruto das próprias condições existentes no Brasil, como o antropólogo Edgard Roquette-Pinto, que preferia utilizar medidas higiênicas e sanitárias para melhorar a vida da população e não sua questão racial e genética (cf. SOUZA, 2006: 164).

Como Vargas era nacionalista, atribuía crédito aos intelectuais nacionais, porém os ideais eugênicos lhe seduziram com maior facilidade do que obras como "Casa Grande e Senzala” de Gilberto Freyre e os discursos de Roquette-Pinto, por exemplo, que retratavam sobre a miscigenação e a realidade social do Brasil - obtendo maior visibilidade apenas alguns anos depois (cf. SOUZA, 2006: 196).

Getúlio Vargas sempre foi nacionalista, preocupando-se com a nação e seu desenvolvimento acima de qualquer coisa, o que ocasionou enormes transformações e indagações à sociedade brasileira da época em diversos setores. As preocupações com o progresso formaram as bases da saúde pública do país, sendo que muito do que foi estabelecido em relação a ministérios e políticas sociais perduram até hoje.

\section{Considerações Finais}

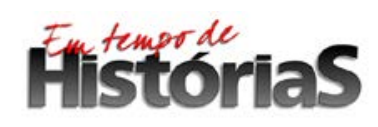

(PPGHIS/UnB) No. 33, Brasília, Ago - Dez 2018 ISSN 2316-1191 
O Governo Provisório foi instaurado após o término da Primeira Guerra Mundial em 1918 e a Crise de 1929. O Brasil passava por um processo de industrialização, e o descontentamento populacional com a política brasileira ocasionou a Revolução de 1930, onde a figura de Getúlio Vargas se mostrou essencial para essa transição e desenvolvimento do país.

Durante a Era Vargas o nacionalismo difundiu-se no Brasil, objetivando criar uma identidade própria para a nação, políticas públicas influenciadas por ideais eugênicos, sanitaristas e higienistas foram implantadas visando o fortalecimento do Estado e da saúde pública. Consolidando leis que vigoram até hoje, Vargas iniciou um processo muito importante em relação à saúde, ao trabalho e à industrialização do país: implantou leis de imigração, leis trabalhistas, criou ministérios, bem como a Justiça eleitoral; além de incentivar no desenvolvimento da nação.

Porém, ao mesmo tempo em que Vargas concedeu benefícios aos trabalhadores, restringiu direitos como a liberdade de expressão, de luta e de greves, por exemplo. Apesar disso, por conta de suas realizações no campo trabalhista, era visto como protetor da classe. Mesmo que por estratégia, suas realizações tiveram enorme peso perante a sociedade que não possuía o amparo necessário anteriormente.

Vargas procurou desenvolver o país, desta forma, as políticas e leis trabalhistas bem como as leis de imigração, saúde e higiene, estavam correlacionadas, pois foram criadas e propagandeadas com um ideal nacionalista. Diferentes autores apontam que seus discursos por vezes confundiam-se com os ideais eugênicos, pois Getúlio buscou criar leis que auxiliassem no processo de formação da identidade brasileira, resultando na desvalorização de alguns grupos que compunham a realidade racial, social e cultural do país.

Assumindo importante papel na política brasileira, principalmente em relação a questões sociais, Vargas consagrou sua imagem entre a população. Diversos autores apontam que o carinho e admiração por Getúlio eram visíveis, principalmente entre a classe trabalhadora, pois através dos discursos nacionalistas tornou-se símbolo do trabalhismo e protetor das classes menos favorecidas. Tendo como ideal a mudança e necessidade de valorizar os próprios recursos e riquezas do país.

Entretanto, durante seu governo Vargas foi ambíguo: da mesma forma em que se voltava às classes menos favorecidas, procurava alicerces entre o exército e a elite; ao mesmo tempo em que utilizava os ideais eugênicos vinculados à pureza racial, atribuía 
valor aos intelectuais nacionais que defendiam a miscigenação. Objetivando evidenciar a imagem e a identidade do Brasil e do brasileiro, por vezes foi contraditório, porém seu propósito sempre foi o mesmo, a ascensão e reconhecimento da pátria.

O fim da Era Vargas concebeu-se apenas em 1964 quando os militares tomam o poder e instauram a ditadura militar, porém o seu legado permanece até hoje, isso porque muito do seu governo ainda está presente, principalmente na legislação eleitoral e trabalhista. Após 88 anos da Revolução de 1930, a imagem do revolucionário, nacionalestadista, Getúlio Dornelles Vargas, ainda permanece presente, mesmo com seus defeitos e contradições.

\section{Fontes:}

BRASIL. Constituição da República dos Estados Unidos do Brasil (de 16 de julho de 1934). Disponível em: <http://www.planalto.gov.br/ccivil_03/constituicao/constituicao34.htm> Acesso em: 22-09-2018.

BRASIL. Constituição da República dos Estados Unidos do Brasil (de 10 de novembro de 1937).

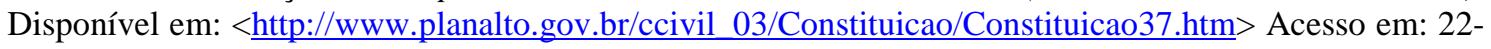
09-2018.

FUNDAÇÃO DE ECONOMIA E ESTATÍSTICA - RS (FEE). A política social brasileira 1930-64: evolução institucional no Brasil e no Rio Grande do Sul. Porto Alegre: A Fundação, 1983.

GERALDO, Endrica. O “perigo alienígena”: política imigratória e pensamento racial no governo Vargas (1930-1945). Departamento de História: Instituto de Filosofia e Ciências Humanas. Universidade Estadual de Campinas, Campinas, 2007, p. 1- 238.

REIS, José Roberto Franco. Higiene Mental e Eugenia: O projeto de "regeneração nacional" da Liga Brasileira de Higiene Mental (1920-1930). Instituto de Filosofia e Ciências Humanas. Universidade Estadual de Campinas, Campinas, 1994, p. 1-353.

STEPAN, Nancy Leys. “Eugenia no Brasil, 1917-1940”. In: Cuidar, controlar, curar: ensaios históricos sobre saúde e doença na América Latina e Caribe. HOCHMAN, Gilberto; ARMUS, Diego (Orgs.). Rio de Janeiro: FIOCRUZ, 2004, p. 330-391.

\section{Referências Bibliográficas}

BARBOSA, Pedro Paulo Lima. Lindolfo Collor e sua proposta de conciliação entre capital e trabalho. Revista Labor, vol. 1, n. 10, 2013, p. 17-31.

BUENO, Newton Paulo. A crise política no final da Era Vargas: Uma interpretação sob a ótica da economia política neo-institucionalista. Estudos Econômicos, São Paulo, vol. 6, n. 1, jan./mar. 2006, p. 181-199.

BOLZAM, Angelina Cortelazzi. Afogados em leis: a CLT e a cultura política dos trabalhadores brasileiros. [resenha]. Cadernos de Direito, Piracicaba, vol. 14, n. 27, jul./dez. 2014, p. 207-210.

CABRAL, Pedro Henrique Ramos. O nacionalismo brasileiro na égide do Estado Getulista. Monografia em Ciência Política - Instituto de Ciência Política, Universidade de Brasília. Brasília, 2016.

CAMARGO, Aspásia. Carisma e personalidade política: Vargas. Da conciliação ao maquiavelismo”. In: As Instituições brasileiras da Era Vargas. D’Araujo Maria Celina (Org.). Rio de Janeiro: UERJ; Fundação Getúlio Vargas, 1999, p. 13-54.

CAPELATO, Maria Helena. O Estado Novo: o que trouxe de novo?. In: Brasil Republicano 2: O tempo do nacional-estatismo: do início da década de 1930 ao apogeu do Estado Novo. FERREIRA, Jorge;

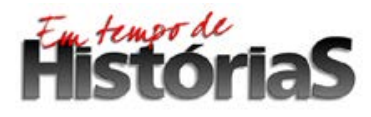

(PPGHIS/UnB) No. 33, Brasília, Ago - Dez 2018 ISSN 2316-1191 
DELGADO, Lucilia de Almeida Neves (Orgs.). $3^{\text {a }}$ ed. Rio de Janeiro: Civilização Brasileira, 2010, p. 107143.

CARDOSO, Adalberto. Estado Novo e Corporativismo. Locus: Revista de História, Juiz de Fora, vol. 13, n. 2, 2007, p. 109-118.

D’ARAUJO, Maria Celina. O Estado Novo. Rio de Janeiro: Jorge Zahar Ed., 2000.

D’ARAUJO, Maria Celina. Estado, classe trabalhadora e políticas sociais. In: Brasil Republicano 2: O tempo do nacional-estatismo: do início da década de 1930 ao apogeu do Estado Novo. FERREIRA, Jorge; DELGADO, Lucilia de Almeida Neves (Orgs.). $3^{\text {a }}$ ed. Rio de Janeiro: Civilização Brasileira, 2010, p. 213239.

FONSECA, Cristina M. Oliveira. A Saúde da Criança na Política Social do Primeiro Governo Vargas. PHYSIS: Revista de Saúde Coletiva. Rio de Janeiro, vol. 3, n. 2, 1993, p. 97-116.

GOMES, Angela de Castro. "Ideologia e trabalho no Estado Novo”. In: Repensando o Estado Novo. PANDOLFI, Dulci (Org.). Rio de Janeiro: Fundação Getúlio Vargas, 1999, p. 53-72.

HOCHMAN, Gilberto. Reformas, instituições e políticas de saúde no Brasil (1930-1945). Educar em Revista. Curitiba, vol. 21, n. 25, 2005, p. 127-141.

KOBAYASHI, Elisabete; FARIA, Lina; COSTA, Maria Conceição da. Eugenia e Fundação Rockefeller no Brasil: a saúde como proposta de regeneração nacional. Sociologias, Porto Alegre, vol. 11, n. 22, jul./dez. 2009, p. 314-351.

MACEDO, Michelle Reis de. Trabalhadores e cidadania no Brasil: o movimento queremista e a democratização de 1945. Programa de Pós-Graduação em História. Universidade Federal Fluminense. Niterói, 2008, p. 1-134.

MARQUES, Elisa Paula. A Loucura Engarrafada: relações alcoolismo-loucura em Florianópolis nas décadas de 1930 a 1960. Programa de Pós-Graduação em História. Universidade Federal de Santa Catarina - Florianópolis, 2017, p. 1-133.

MENDONÇA, Sônia Regina de. “As bases do desenvolvimento capitalista dependente da industrialização restringida à internacionalização”. In: História Geral do Brasil. LINHARES, Maria Yedda (Org.). 9ª ed. Rio de Janeiro: Elsevier, 1990, p. 327-350.

MENDONÇA, Sônia Regina de. "Parte B: Estado e sociedade: a consolidação da República oligárquica”. In: História Geral do Brasil. LINHARES, Maria Yedda (Org.). 9a ed. Rio de Janeiro: Elsevier, 1990, p. 316-326.

MOURELLE, Thiago Cavaliere. Guerra pelo poder: a Câmara dos Deputados defronta Vargas (19341935). Departamento de História: Instituto de Ciências Humanas e Filosofia. Universidade Federal Fluminense, Niterói, 2015, p. 1-254.

MOURELLE, Thiago Cavaliere. Getúlio Vargas, o medo do golpe e a questão dos reajustes salariais em 1935: o sim aos militares e o não aos civis. Dimensões, Espírito Santo, vol. 34, 2015, p. 436-456.

PANDOLFI, Dulce Chaves. “Os anos 1930: as incertezas do regime”. In: Brasil Republicano 2: O tempo do nacional-estatismo: do início da década de 1930 ao apogeu do Estado Novo. FERREIRA, Jorge; DELGADO, Lucilia de Almeida Neves (Orgs.). $3^{\text {a }}$ ed. Rio de Janeiro: Civilização Brasileira, 2010, p. 1337.

PONTE, Carlos Fidelis. “O sanitarismo e os projetos de nação”. In: Na corda bamba de sombrinha:a saúde no fio da história. FIDELIS, Carlos; FALLEIROS, Ialê (Org.). Rio de Janeiro: Fiocruz/COC; Fiocruz/EPSJV, 2010, p. 75-78.

PONTE, Carlos Fidelis. “A liga pró-saneamento do Brasil e a criação do Ministério da educação e saúde”. In: Na corda bamba de sombrinha: a saúde no fio da história. FIDELIS, Carlos; FALLEIROS, Ialê (Org.). Rio de Janeiro: Fiocruz/COC; Fiocruz/EPSJV, 2010, p. 96-100.

PONTE, Carlos Fidelis. "Tempos de guerra: o campanhismo entra em cena”. In: Na corda bamba de sombrinha: a saúde no fio da história. FIDELIS, Carlos; FALLEIROS, Ialê (Org.). Rio de Janeiro: Fiocruz/COC; Fiocruz/EPSJV, 2010, p. 101-110.

\section{Filistororias}


PONTE, Carlos Fidelis. “Entre a saúde pública e a medicina previdenciária”. In: Na corda bamba de sombrinha: a saúde no fio da história. FIDELIS, Carlos; FALLEIROS, Ialê (Org.). Rio de Janeiro: Fiocruz/COC; Fiocruz/EPSJV, 2010, p. 113-120.

REIS, José Roberto Franco. "Vargas e a previdência: entre a dádiva e o direito”. In: Na corda bamba de sombrinha:a saúde no fio da história. FIDELIS, Carlos; FALLEIROS, Ialê (Org.). Rio de Janeiro: Fiocruz/COC; Fiocruz/EPSJV, 2010, p. 121-137.

RIZOTTI, Maria Luiza Amaral. Estado e Sociedade Civil na História das Políticas Sociais Brasileiras. Revista Semina: Ciências Sociais e Humanas, Londrina, v. 22, n. 1, set. 2001, p. 39-56.

ROCHA, Simone. Educação eugenica na constituição brasileira de 1934. X ANPED SUL - Seminário de Pesquisa em Educação da Região Sul, Florianópolis, 2014, p. 1-14.

ROSSI, Vanberto José. As duas faces do primeiro Governo Vargas. Revista Eletrônica do CEMOP. Sumaré, n. 1, 2012, p. 1-7.

SCHNEIDER, Eduarda Maria; MEGLHIORATTI, Fernanda Aparecida. A influência do movimento eugênico na constituição do sistema organizado de educação pública do Brasil na década de 1930. IX ANPED SUL - Seminário de Pesquisa em Educação da Região Sul, 2012, p. 1-12.

SIKORA, Mafalda Ales. As políticas de imigração no Brasil nos séculos XIX e XX e o desenvolvimento de territórios: Estudo de Caso da Colônia Dom Pedro II - Campo Largo - Paraná. Programa de PósGraduação em Tecnologia. Universidade Tecnológica Federal do Paraná. Curitiba, 2014, p. 1-208.

SILVA, Fernanda Xavier da. As Constituições da Era Vargas: uma abordagem à luz do pensamento autoritário dos anos 30. Política e Sociedade, Florianópolis, vol. 9, n. 17, 2010, p. 259-288.

SOUSA, Cynthia. Pereira de. "Saúde, educação e trabalho de crianças e jovens: a política social de Getúlio Vargas”. In: Capanema: o ministro e seu ministério. GOMES, Angêla de Castro (Org.). Rio de Janeiro: Fundação Getúlio Vargas, 2000, p. 221-249.

SOUZA, Vanderlei S. de. As Idéias Eugênicas No Brasil: ciência, raça e projeto nacional no entre- guerras. Revista Eletrônica História em Reflexão, Dourados, vol. 6, n. 11, jan./jun. 2012, p. 1-23.

SOUZA, Vanderlei Sebastião de. A política biológica como projeto: a "eugenia negativa” e a construção da nacionalidade na trajetória de Renato Kehl (1917-1932). Programa de Pós-Graduação em História das Ciências da Saúde da Casa de Oswaldo Cruz/ Fiocruz. Rio de Janeiro, 2006.

TEIXEIRA, Francisco Maria Pires. “Crise e Ruptura da República Velha”. In: História Concisa do Brasil. $2^{\mathrm{a}}$ ed. São Paulo: Global, 2000, p. 241-255.

TEIXEIRA, Francisco Maria Pires. “O tempo de Vargas, 1930-1945”. In: História Concisa do Brasil. $2^{\mathrm{a}}$ ed. São Paulo: Global, 2000, p. 267-283. 